\title{
Mapping Posidonia oceanica meadows through time A story of precision, evaluation and fragmentation
}

Arnaud Abadie $^{1,2}$, Matthieu Jousseaume ${ }^{3}$, Pierre Lejeune ${ }^{1}$ and Sylvie Gobert ${ }^{2}$

Contact: arnaudabadie@aol.fr
Anthention STARESO

CART'0)

'Cart'o, Martinique, France

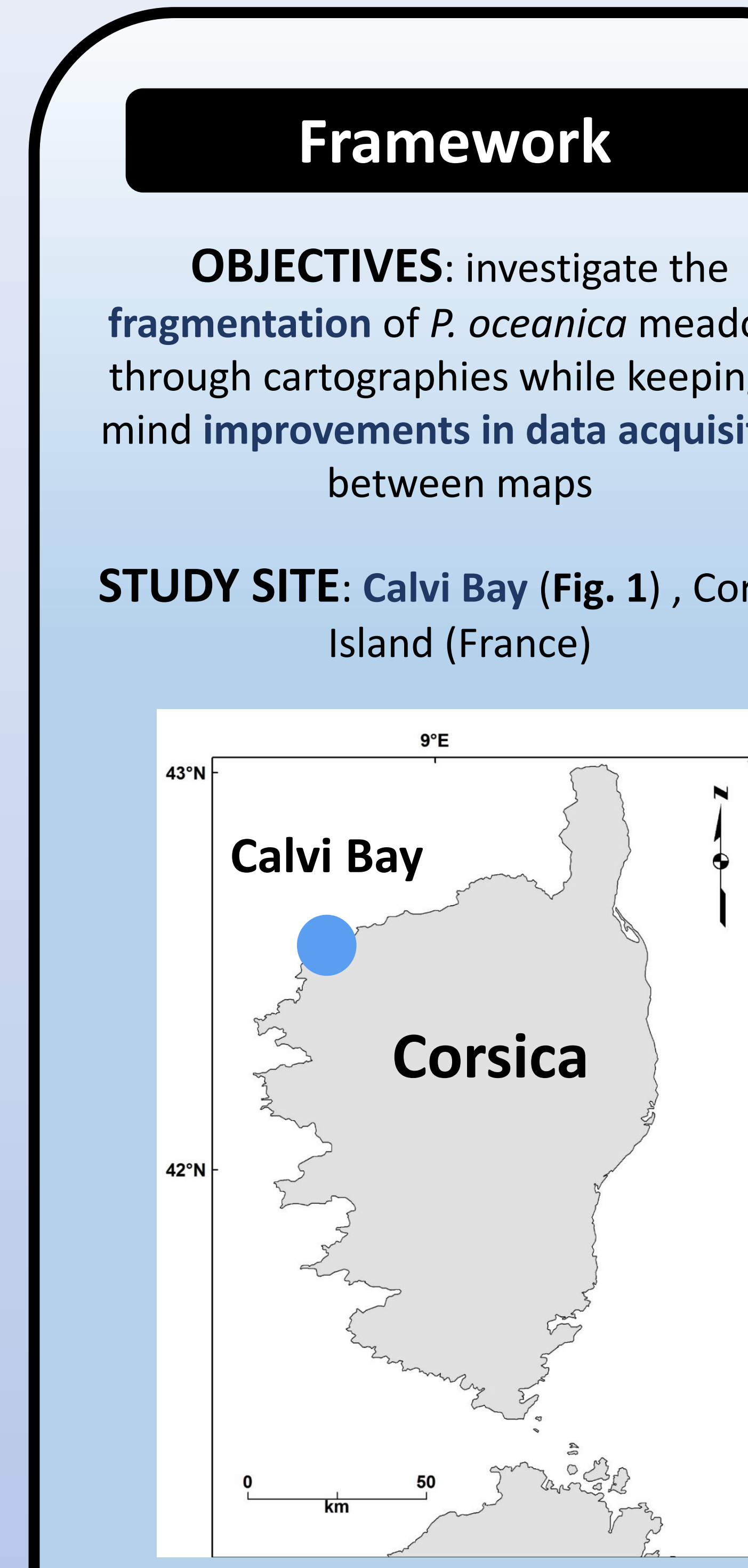

Figure 1: location of the study site METHOD: aerial photographs, side scan sonar (Fig. 2), scuba diving identification, bathymetry, Geographical Information System (GIS), Computeraided design (CAD)

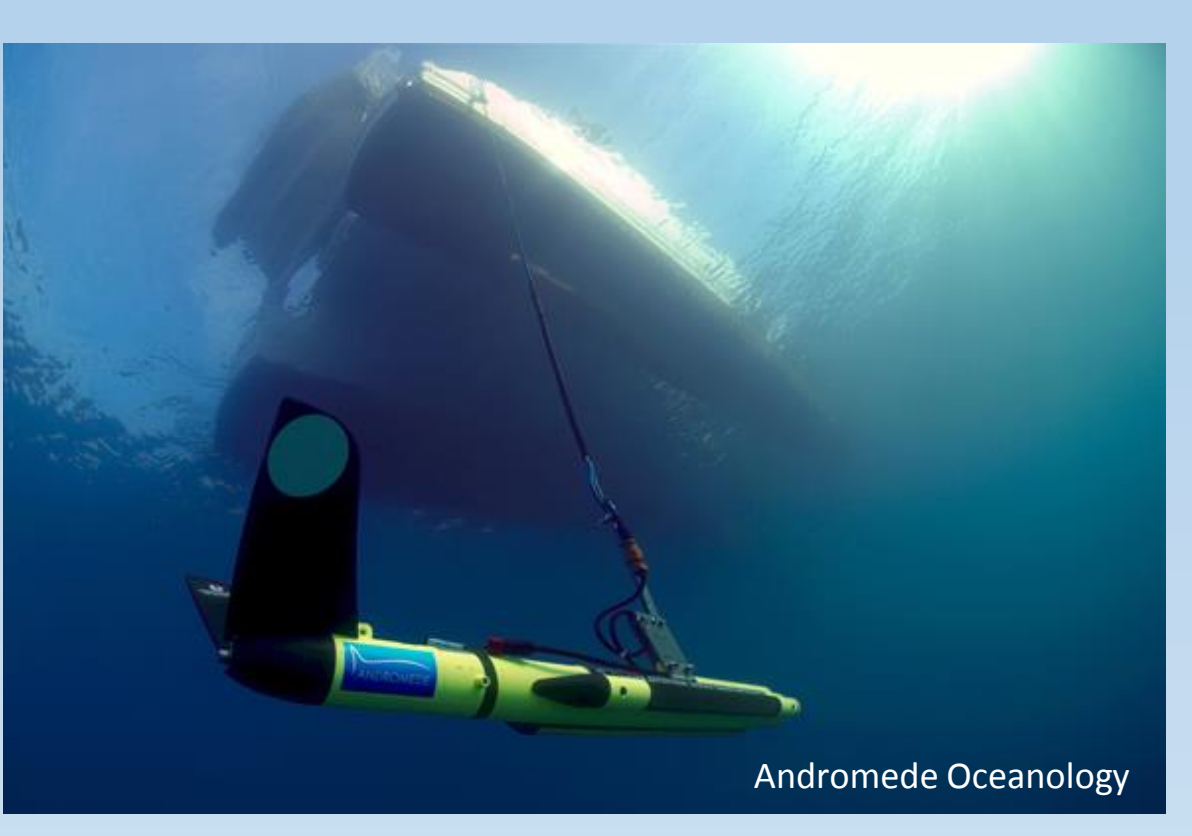

Figure 2: side scan sonar

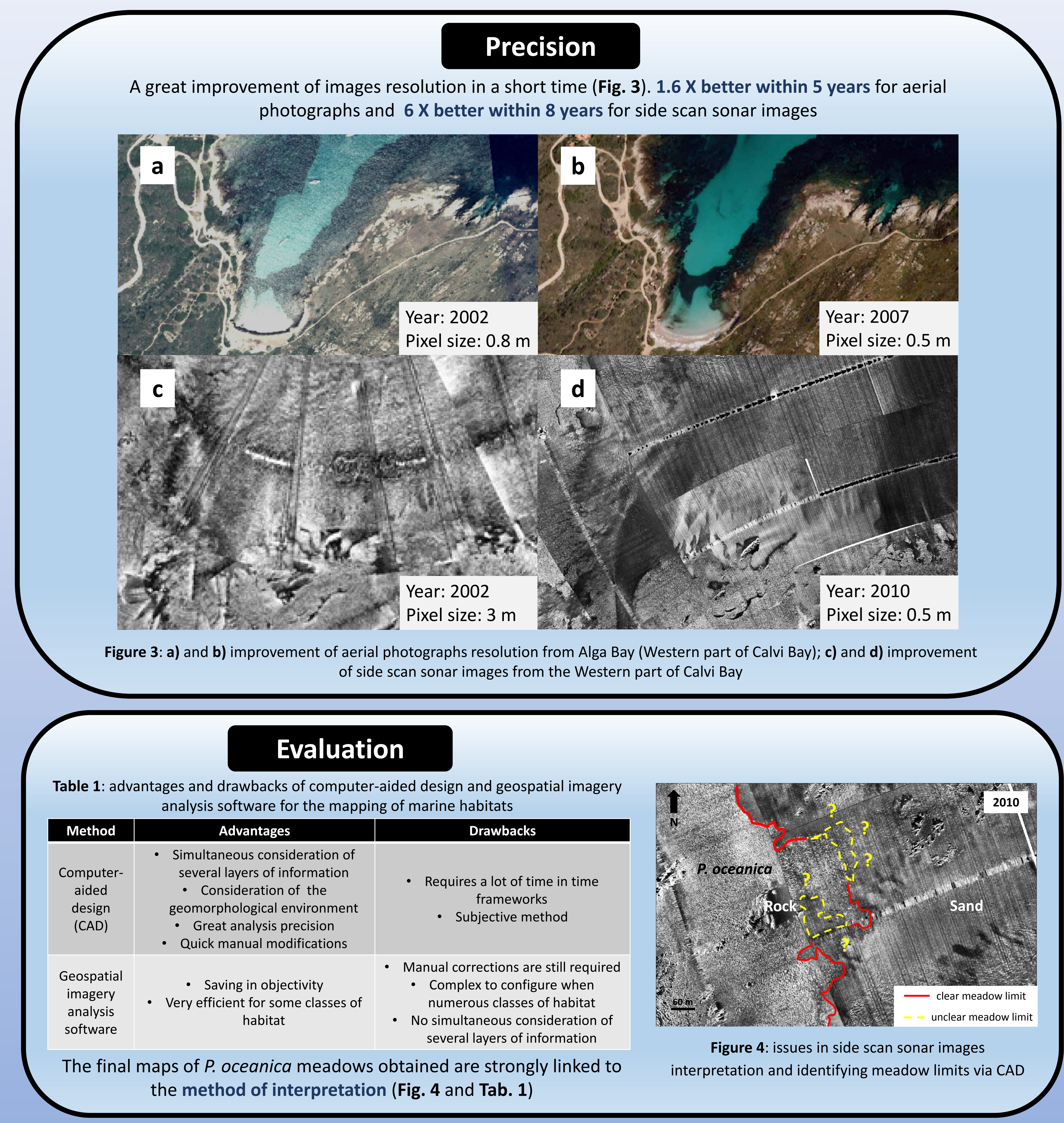

\section{Fragmentation}

A clear regression of $P$. oceanica meadows is observed in the bay (Fig. 5) and especially near the lower limit (Tab. 2). The extent of fragmentation within such a short period cannot be explained by natural or anthropogenic phenomenon given the low intensity of human activities in the bay

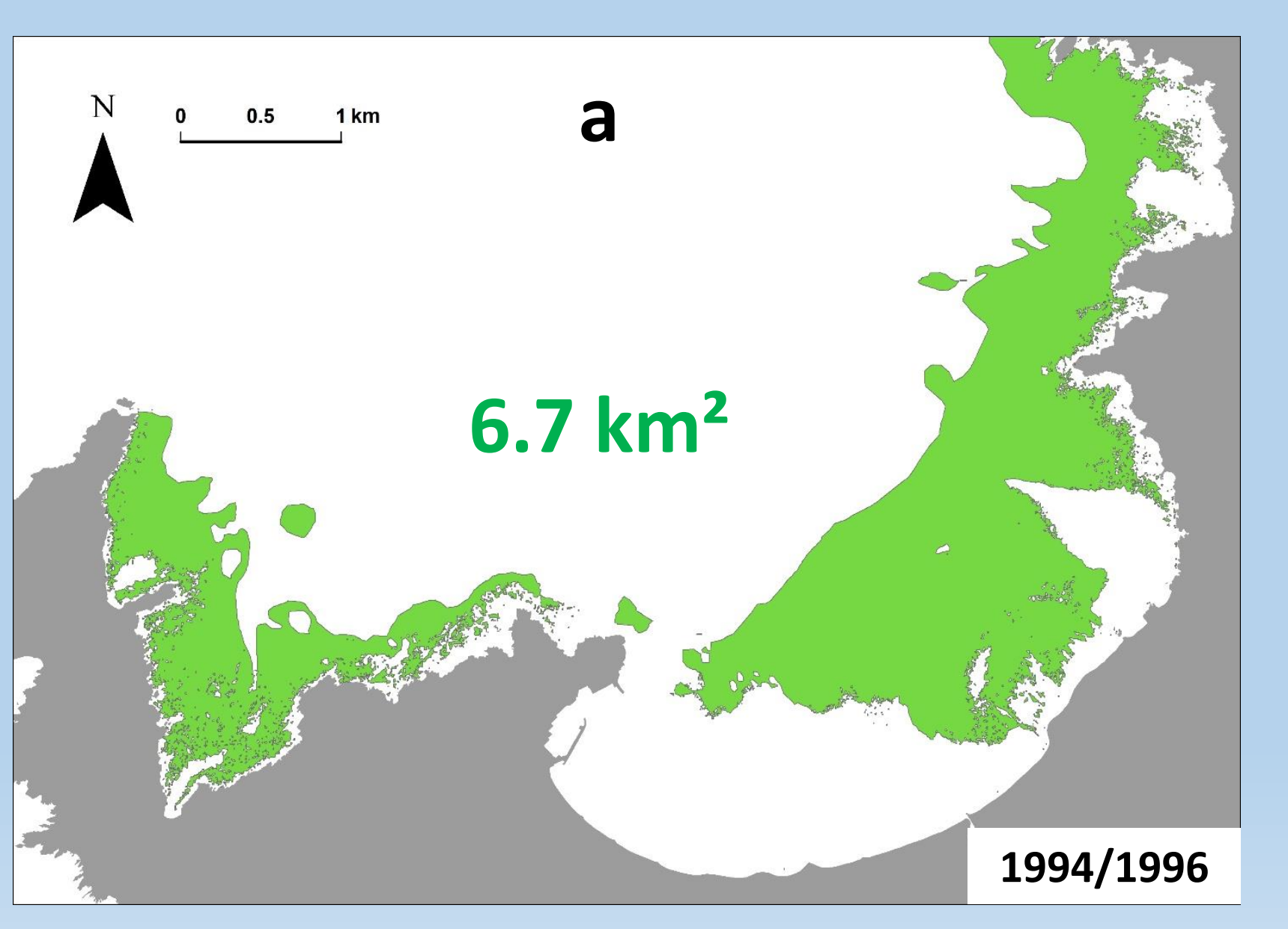

Table 2: Percentage of $P$. oceanica meadows coverage according to
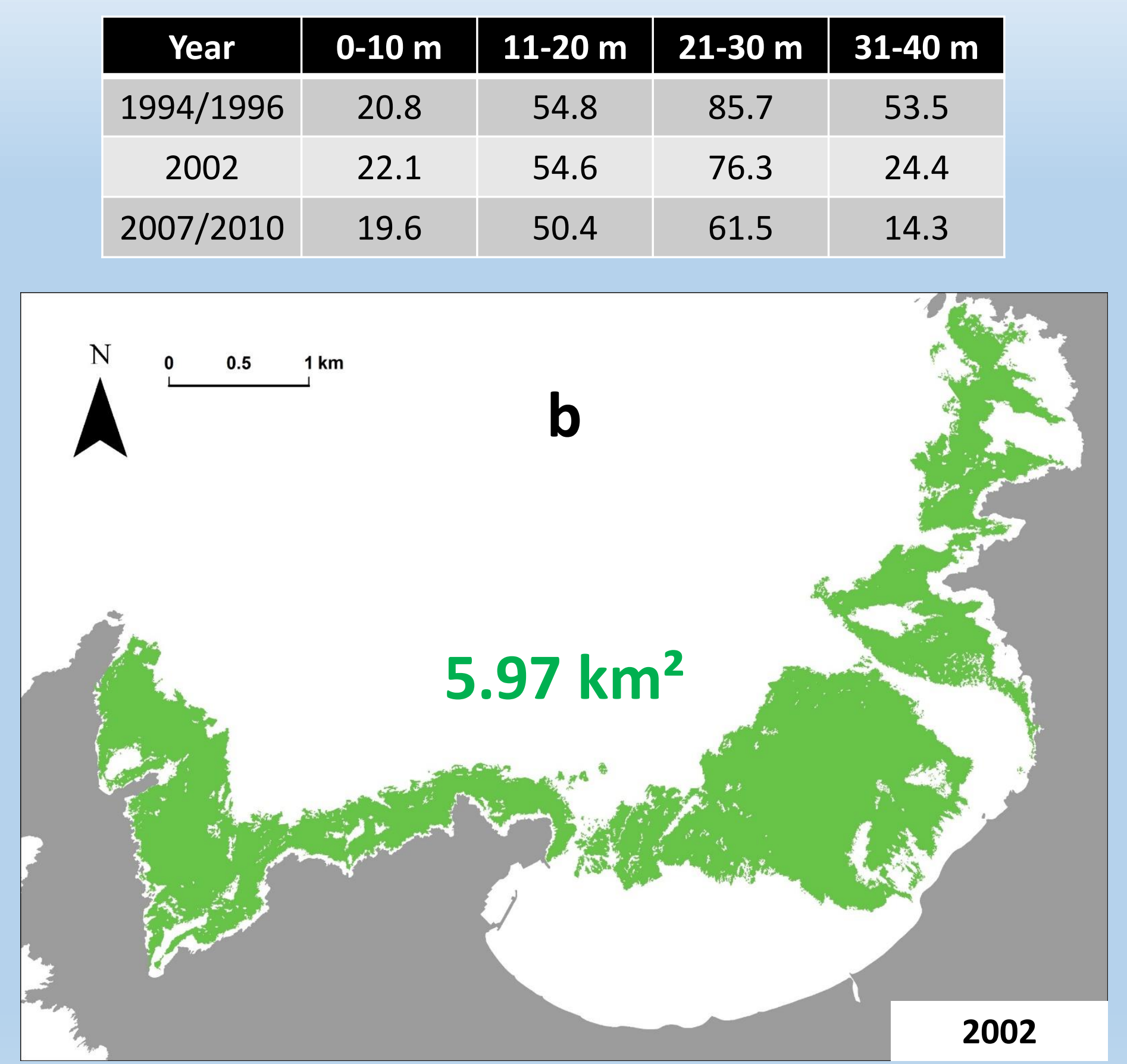

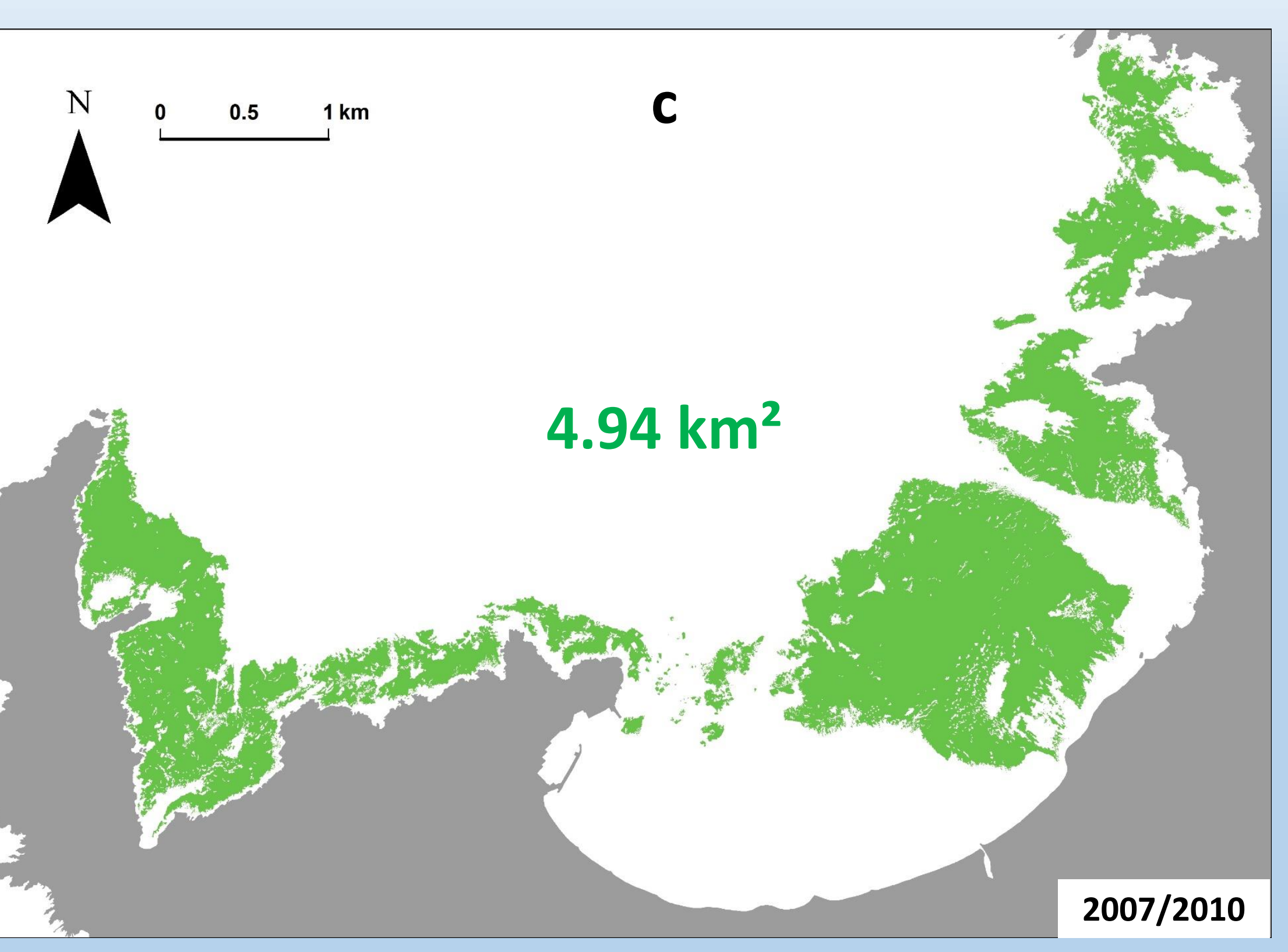

Figure 5: maps of Posidonia oceanica meadows and their area in Calvi Bay: a) 1994/1996 (source: Pasqualini, 1997) b) 2002; c) 2007/2010

\section{Conclusion}

1.Issues in assessing the real fragmentation of the meadows through time are linked with the method as well as a strong and quick increase in quality of the data required to built $P$. oceanica maps
2. The high resolution of the last $P$. oceanica meadow maps allows to study other aspects than fragmentation, like their structure and function

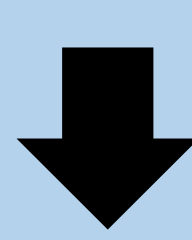

Seascape ecology is study was carried out thanks to the found of the Territorial Collectivity of Corsica and the Water Agency through the STARE-CAPMED program 